\title{
UN MORMÂNT DIN PERIOADA MEDIEVALĂ DESCOPERIT LA IP-DEALUL BiSERICII (JUDEȚUl SĂLAJ)
}

\author{
DAN BĂCUEȚ-CRIȘAN \\ ZSOLT CSÓK \\ TIMEA KERESZTES
}

\begin{abstract}
REZUMAT:
Situl arheologic din punctul Dealul Bisericii este dispus în centrul localităţii Ip, pe o terasă înaltă de pe partea dreaptă a văii Barcăului și a fost identificat în urma unor cercetări de suprafață efectuate în anul 2002. Prima investigare arheologică a avut loc în anul 2009 printr-o săpătură arheologică preventivă, soldată cu identificarea unui număr de 10 complexe arheologice din epoci diferite: epoca bronzului, epoca romană, evul mediu timpuriu. Complexul arheologic care face obiectul prezentului demers este un mormânt de inhumație (complexul C. 5/2009), care avea ca inventar o cataramă de curea confecționată din bronz. Pe baza analogiilor constatate, având în vedere și începuturile funcționării bisericii medievale, putem presupune că datarea mormântului medieval C. 5/2009 poate fi plasată cel mai probabil în secolul al XV-lea.
\end{abstract}

\section{Abstract: A Medieval Grave discovered at Ip - Dealul Bisericit (Sălaj County)}

The archeological site from Ip - Dealul Bisericii is located in the center of Ip village, on a high terrace on the right side of the Barcău valley. The site was identified during the surface research carried out in 2002. The first archaeological investigation took place in 2009 through a rescue excavation resulting in the identification of a number of 10 archeological features from different epochs: bronze age, roman period, medieval period. The archeological feature that is the object of the present approach is a inhumation grave (feature C. 5/2009) which had as inventory a belt buckle made of bronze. Based on the analogies, considering also the beginnings of the functioning of the medieval church, we can assume that the dating of medieval grave C. 5/2009 can be placed most likely in the $\mathrm{XV}^{\text {th }}$ century.

CUVINTE CHEIE: cercetări arheologice preventive, complexe arheologice, medieval, mormânt de inhumație, cataramă din bronz.

KEYWORDS: rescue excavations, features, medieval, inhumation grave, bronze buckle.

\section{Localizarea obiectivului arheologic. Istoricul cercetărilor}

Localitatea Ip (com. Ip) se află pe valea râului Barcău, dezvoltându-se în prezent pe ambele maluri ale râului. Situl arheologic din punctul Dealul Bisericii este dispus în centrul localității Ip, pe o terasă înaltă de pe partea dreaptă a văii Barcăului (Pl. I/A) și a fost identificat în urma unor cercetări de suprafață efectuate în anul 2002'. Prima investigare arheologică a avut loc în anul 2009 printr-o săpătură arheologică preventivă̌ soldată cu identificarea unui număr de 10 complexe arheologice (Pl. I/B), din epoci diferite: epoca bronzului, epoca romană, evul mediu timpuriu ${ }^{3}$. Dintre artefactele descoperite în anul 2009, doar cele medievale timpurii au fost publicate ${ }^{4}$.

\section{Condiţiile descoperirii}

După cum s-a mai precizat și cu alte ocaziii ${ }^{5}$ o mare parte a suprafaței care trebuia investigată arheologic a fost afectată deja de fundațiile unei gospodării mai vechi (locuința, anexele, pivnița și gardurile), prin urmare și o

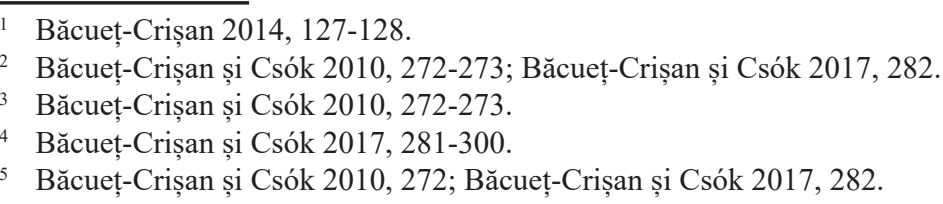




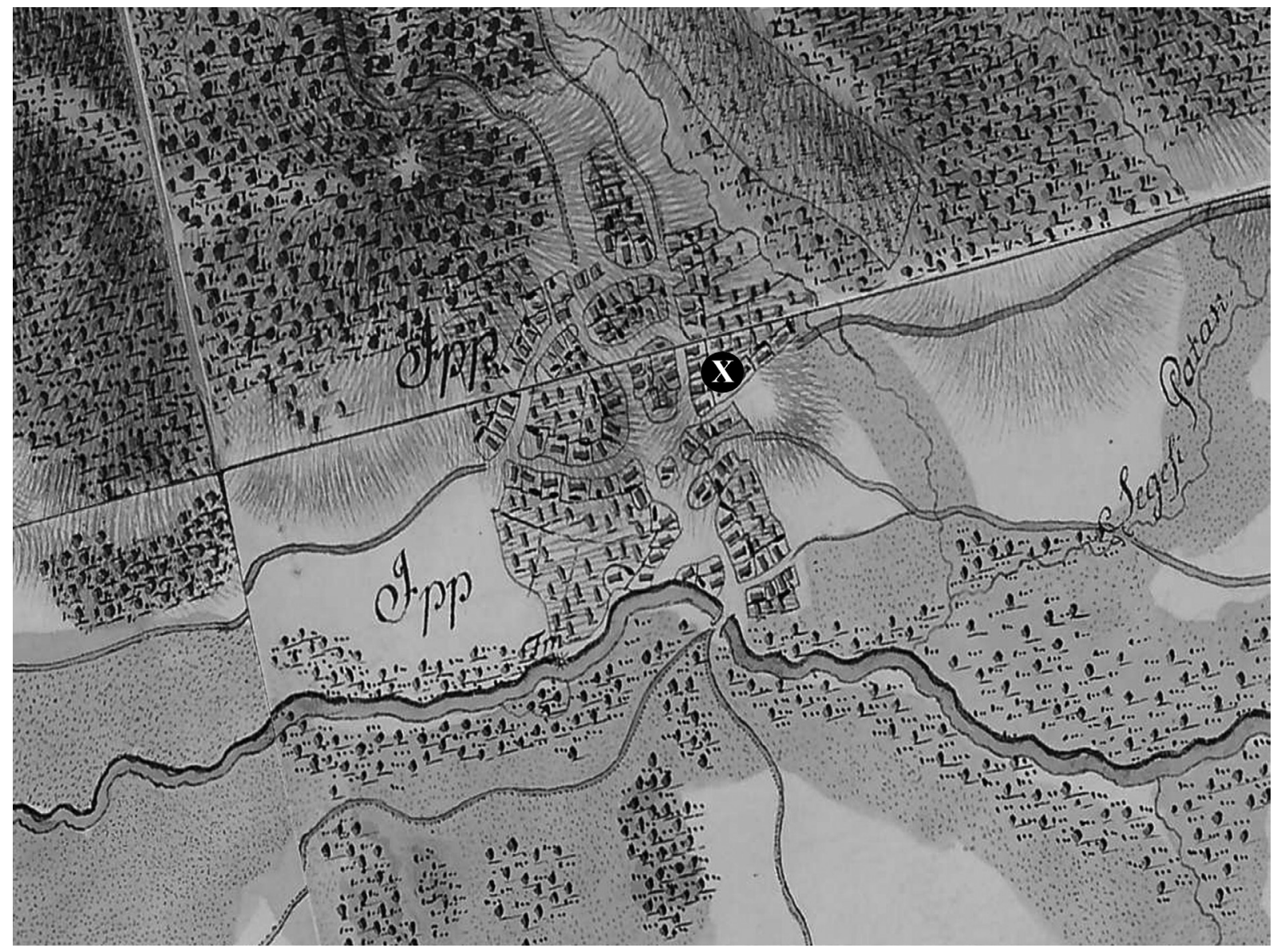

Fig. 1. Localizarea sitului de la Ip - Dealul Bisericii (marcat cu X) pe prima ridicare topografică militară austriacă ${ }^{6}$.

parte din complexele identificate în săpătură au fost deranjate din vechime, fapt constatat pe parcursul derulării cercetărilor arheologice preventive (Pl. I/B). Complexul arheologic care face obiectul prezentului demers a fost conturat la adâncimea de 0,60 m față de nivelul actual de călcare și este o descoperire cu caracter funerar.

\section{Caracteristicile complexului arheologic. Rit și ritual funerar}

Complexul C. 5/2009. Mormânt de inhumație (orientare NV-SE) afectat de amenajările din epoca modernă. Complexul s-a conturat în lutul gălbui (steril din punct de vedere arheologic), sub forma unei pete de culoare negricioasă de formă alungită ale cărei margini nu au putut fi stabilite cu exactitate. Din păcate, partea inferioară a scheletului (zona picioarelor) a fost cea mai puternic afectată de intervențiile ulterioare. Poziția scheletului indică faptul că, defunctul a fost așezat întins pe spate, cu mâinile pe lângă corp, brațul drept ușor îndoit din cot și palma adusă pe bazin (Pl. II/A).

\section{Inventarul funerar. Caracteristici formale}

În ciuda afectărilor din vechime, în mormântul C. 5/2009, în zona bazinului, lângă brațul drept a fost descoperită o cataramă din bronz de la o curea (pl. II/1a-b). Catarama este de formă semicirculară cu o latură dreaptă, asemănătoare literei D. Corpul cataramei este lat, ornamentat cu mai multe elemente decorative: pe marginea interioară sunt dispuse cercuri mici (realizate prin batere), marginea exterioară este decorată (prin incizare) cu linii scurte și dese, între acestea fiind intercalate linii mai lungi, dispuse câte trei (două oblice și una dreaptă la mijloc). Spinul cataramei (rectangular în secțiune) este de asemenea decorat (prin incizare) cu grupuri de linii drepte (verticale) trasate paralel (Pl. II/1a-b).

\footnotetext{
sursa: http://mapire.eu/en/map/ firstsurvey/?bbox $=2511821.0730505157 \% 2 \mathrm{C} 5977621.643585576 \% 2 \mathrm{C} 2520993.516444737 \% 2 \mathrm{C} 5981935.5583694205$.
} 


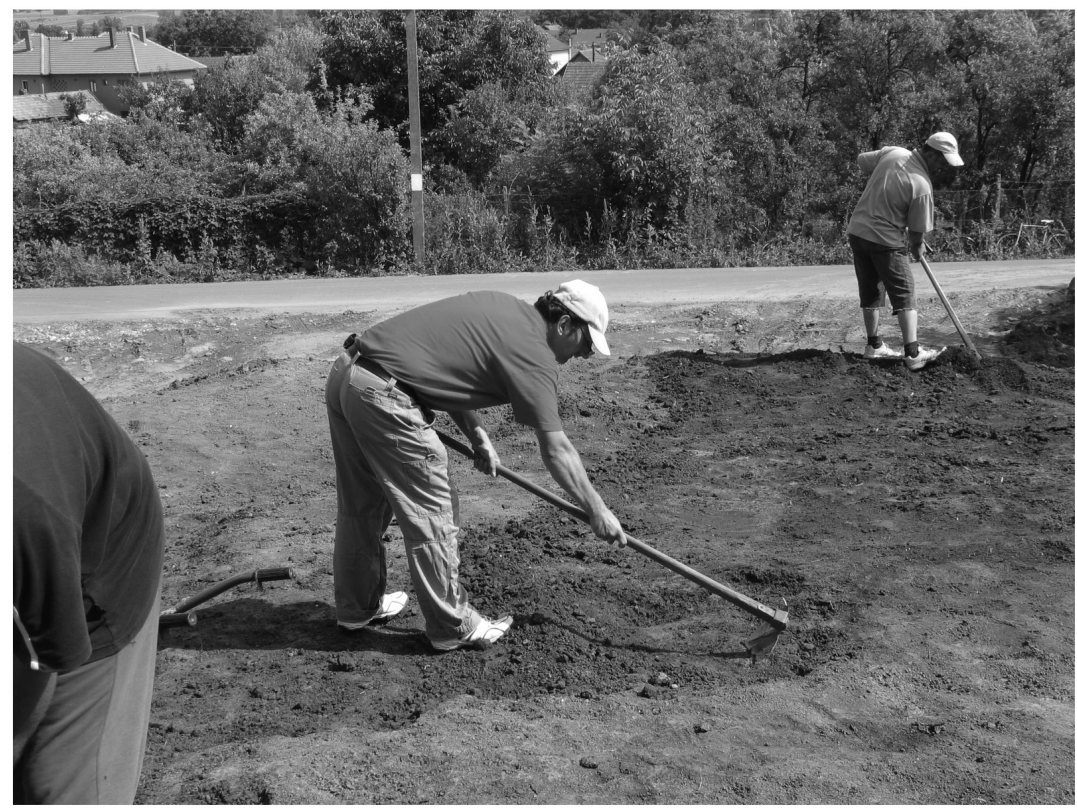

A

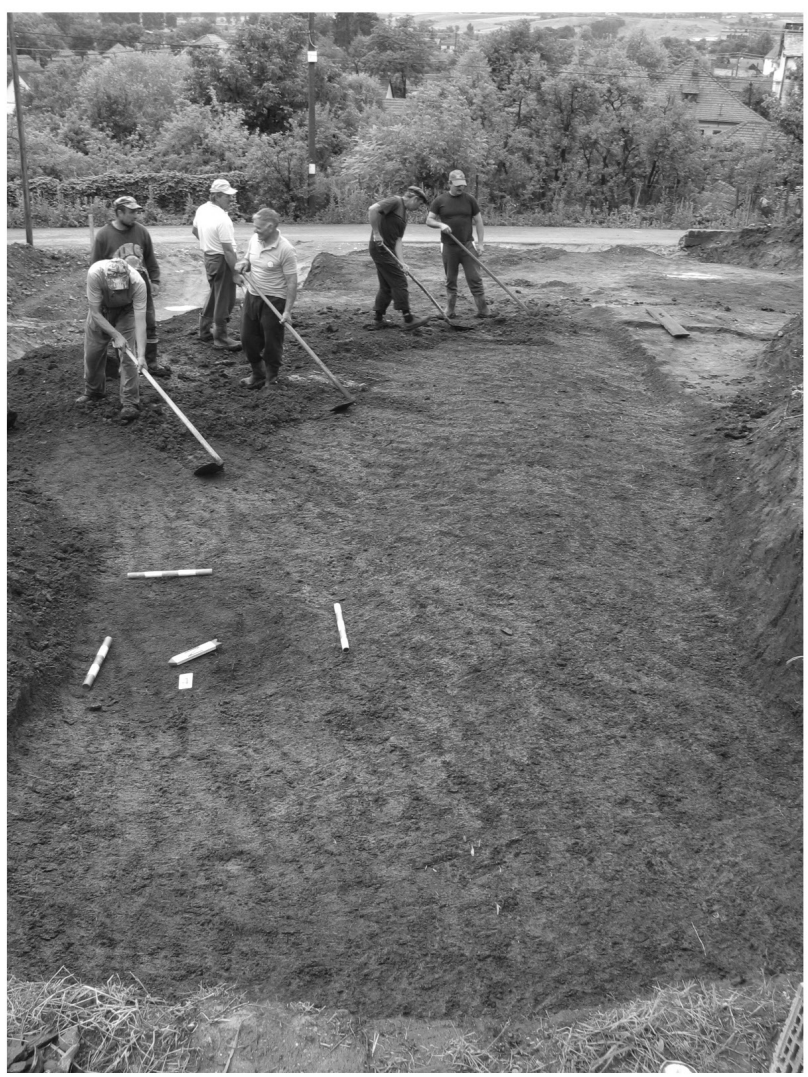

Fig. 2. Ip - Dealul Bisericii. Imagini din timpul cercetărilor (A-B) (arhiva foto Muzeul Județean de Istorie și Artă Zalău). 


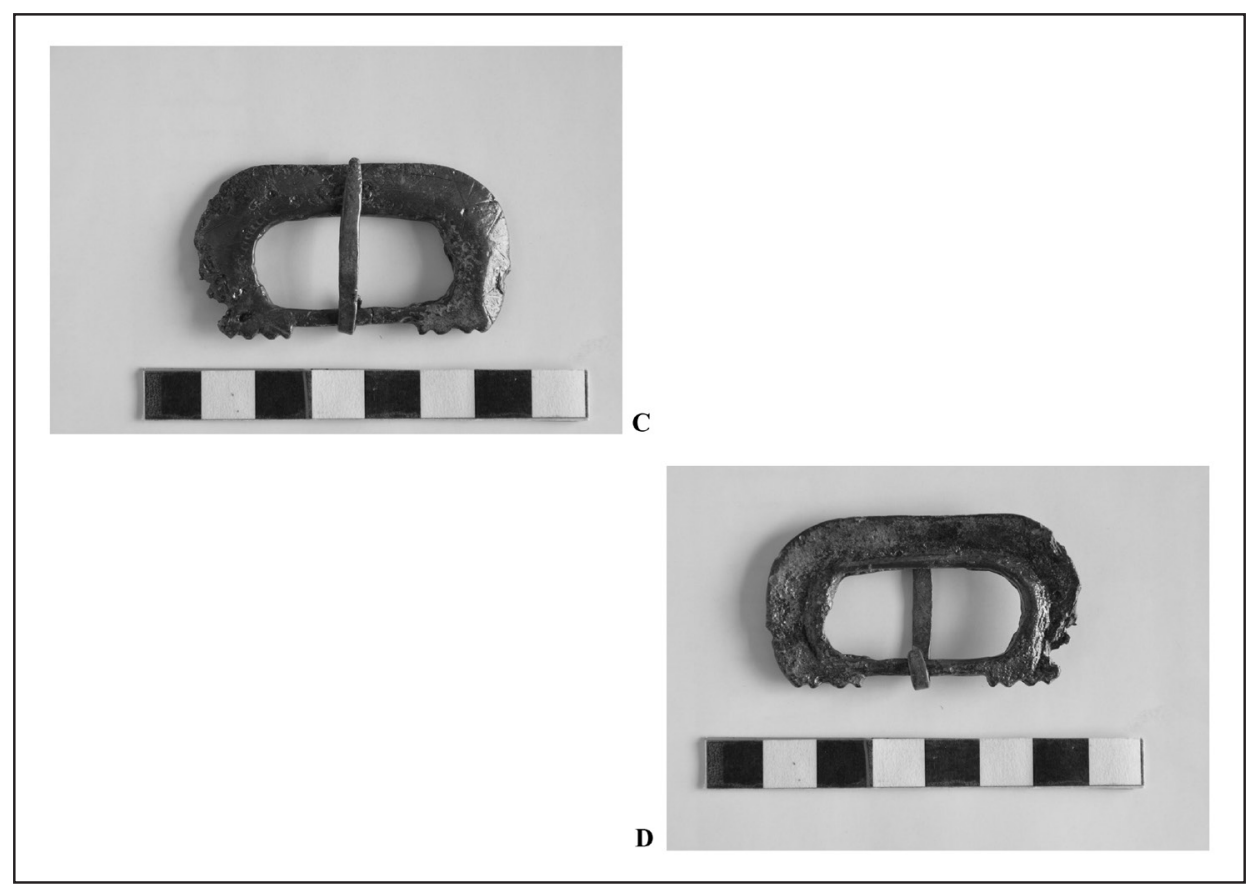

Fig. 3. Ip - Dealul Bisericii. Mormântul C. 5/2009. Cataramă din bronz (arhiva foto Muzeul Județean de Istorie și Artă Zalău).

\section{Considerații (prudente) privind încadrarea cronologică}

Din păcate, cu excepția cataramei din bronz, nu dispunem de alte artefacte cu care să putem opera în vederea stabilirii cronologiei mormântului descoperit la Ip - Dealul Bisericii. Catarame medievale de acest tip (formă semicirculară cu o margine dreaptă, în forma literei D) au fost identificate în descoperiri funerare databile în secolele XIII-XIV7 dar și în secolele XIV-XV ${ }^{8}$, unele exemplare fiind prevăzute cu placă de fixare (uneori decorată) pe cureaua din

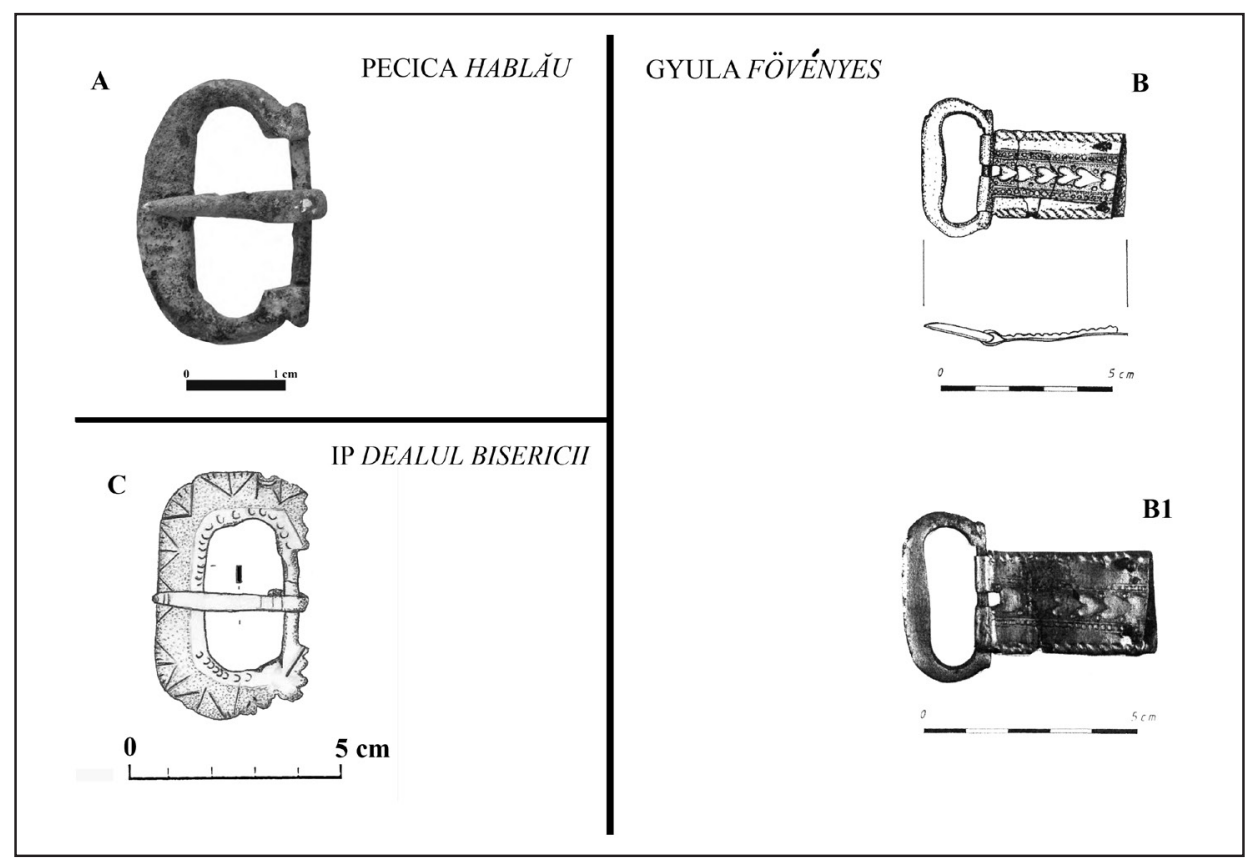

Fig. 4. Exemple de catarame de formă semicirculară cu o margine dreaptă (în forma literei $D$ ) (A după Oța și Comșa 2017; B-B1 după Gábor 2006).

Fingerlin 1971, Pl. 15/15, Pl. 15/17, 433 (catalog nr. 389 și nr. 390); Oța 2016, 52.

8 Whitehead 1996, catalog nr. 66-67. 
piele. Facem precizarea că, deocamdată, în literatura de specialitate (studiată de noi) nu am identificat un exemplar identic cu cel de la Ip - Dealul Bisericii. Totuși, în vederea creionării unei (posibile) cronologii (pentru mormântul de la Ip), menționăm cataramele în forma literei D din cimitirele de la Pecica - Hablău (secolele XIII-XIV) ${ }^{9}$ și Gyula - Fövényes (mormântul nr. 34, mormânt de copil cu cataramă cu placă de fixare decorată), datat la sfârșitul secolului al XIV-lea - secolul al XV-lea (posibil doar secolul al XV-lea) ${ }^{10}$.

Mormântul (C. 5/2009) cercetat la Ip - Dealul Bisericii făcea parte din cimitirul dezvoltat în jurul bisericii situată în imediata apropiere a zonei pe care s-au efectuat în anul 2009 săpăturile arheologice preventive. În ceea ce privește evoluția bisericii, cea mai veche fază de construcție a acesteia datează din prima jumătate a secolului al XV-lea ${ }^{11}$. Având în vedere cataramele menționate mai sus (Fig. 4), dar mai ales începuturile funcționării bisericii medievale, putem presupune că datarea mormântului C. 5/2009 poate fi plasată cel mai probabil în secolul al XV-lea.

În ceea ce privește satul Ip, primele informații scrise despre acesta au apărut într-un document din anul 1205, în care se fac referiri la un proces soluționat la Capitlul de la Oradea în legătură cu stăpânirile vânătorilor de zimbri din sat (venatores bubalorum de villa $Y p u)^{12}$. În secolul al XIII-lea, localitatea mai apare ca villa Ip (menționare în anul 1213), iar în secolul al XV-lea ca Iph (menţionări în anii 1414, 1435 și 1450) ${ }^{13}$.

\section{BIBLIOGRAFIE}

Băcueț-Crișan, D. 2014. Contribuţii arheologice privind nord-vestul României în sec. VII-XI. Cercetări în Depresiunea Silvaniei. Cluj-Napoca: Editura Mega/Editura Porolissum.

Băcueț-Crişan, D. și Csók, Zs. 2010. Şantierul arheologic Ip - Dealul Bisericii. Cronica Cercetărilor Arheologice din România. Campania 2009, A XLIV-a Sesiune Națională de Rapoarte Arheologice, Suceava, 27 - 30 Mai 2010 : 272-273. București: Muzeul Național de Istorie a României.

Băcueţ-Crişan, D. și Csók, Zs. 2017. O locuință medievală timpurie descoperită la Ip - Dealul Bisericii (județul Sălaj), în Fl. Mărginean, I. Stanciu, D. Băcueț-Crișan (Ed.) Locuirea medievală timpurie din Transilvania și vecinătăți: 281-300. Cluj-Napoca: Editura Mega.

Fingerlin, I. 1971. Gürtel des hohen und späten Mittelalters, München/Berlin: Editura Deutscher Kunstverlag. Gábor, G. 2006. Középkori pártaövek Békés Megyében. A Békés Megyei Múzeumok Közleményei 28: 111-142.

Karácsonyi, J., Borovszky, S. 1903. Regestrum Varadinense examinum ferris candentis ordino chronologico digestum, descripta effigie editionis a. 1550 illustratum sumptibusque Capituli Varadinensis lat. rit. . Budapest: Editura A Váradi Káptalan.

Major, M. 1999. Ipp, în Szilágysági magyarok: 379-383. București/Cluj-Napoca: Editura Kriterion.

Oța, S. 2016. Burials with belts. Rank insignia or dress accessories (12th - 15th centuries A. D.), în I Țiplic. M. Țiplic, M. Crîngaci Țiplic (eds.), Arh. In. (I). Medieval Changing Landscape. Settlements, Monasteries and Fortifications: 43-61. Sibiu: Editura Astra Museum.

Oța, S. și Comșa, Al. 2017. Despre un mormânt descoperit la Pecica-Hăblău (Mănăstirea lui Ahtum), județul Arad. Cercetări Arheologice XXIV: 229-246.

Whitehead, R. 1996. Buckles (1250-1800). Essex: Editura Greenlight Publishing.

Suciu, C. 1967. Dicționar istoric al localităților din Transilvania. București: Editura Academiei RSR.

\footnotetext{
9 Oța și Comșa 2017, 232.

10 Gábor 2006, 126-127, 9. Kép/2, 12. Kép/2.

11 Major 1999, 381.

12 Karácsonyi și Borovszky 1903, 155.

13 Suciu 1967, 310
} 


\section{LIST OF PLATES}

Pl. I. Location of the site Ip - Dealul Bisericii (X). Google Earth satellite image (A). The plan of the rescue excavations made in 2009 and the features distribution (after Băcueț-Crișan, Csók 2017) (B).

Pl. II. Ip - Dealul Bisericii. Feature C. 5/2009 (medieval grave) (A). Bronze buckle (1a-1b).

\section{LIST OF FIGURES}

Fig. 1. Location of the site Ip-Dealul Bisericii (X) on the first Austrian military topographic survey.

Fig. 2. Ip - Dealul Bisericii. Images during the rescue excavations (A-B) (History and Art Museum Zalău, photo archive).

Fig. 3. Ip - Dealul Bisericii. Medieval grave C. 5/2009. Bronze buckle (History and Art Museum Zalău, photo archive).

Fig. 4. Examples of “D letter type” buckles (A after Oța și Comșa 2017; B-B1 after Gábor 2006).

DAN BĂCUET⿱-CRIȘAN

Muzeul Județean de Istorie și Artă Zalău

bacuetz@yahoo.com

ZSOLT CSÓK

Muzeul Național de Istorie a Transilvaniei csok.zsolt@gmail.com

TIMEA KERESZTES

Muzeul Județean de Istorie și Artă Zalău keresztes.timea@yahoo.com 


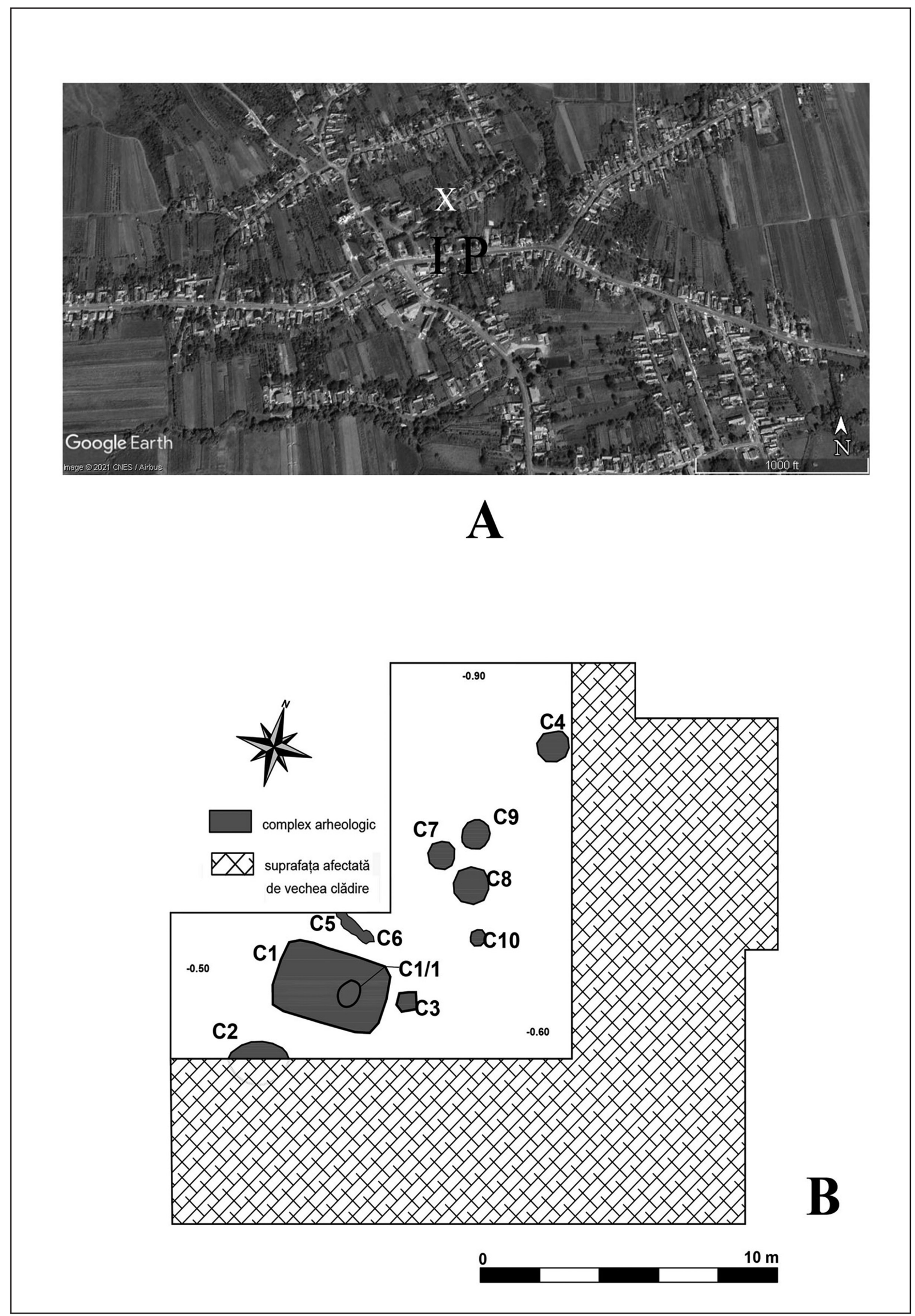

Pl. I. Localizarea sitului de la Ip - Dealul Bisericii (marcat cu X). Imagine satelitară Google Earth (A). Planul cercetărilor arheologice preventive efectuate în anul 2009 și dispunerea complexelor arheologice (după Băcueț-Crișan și Csók 2017) (B). 


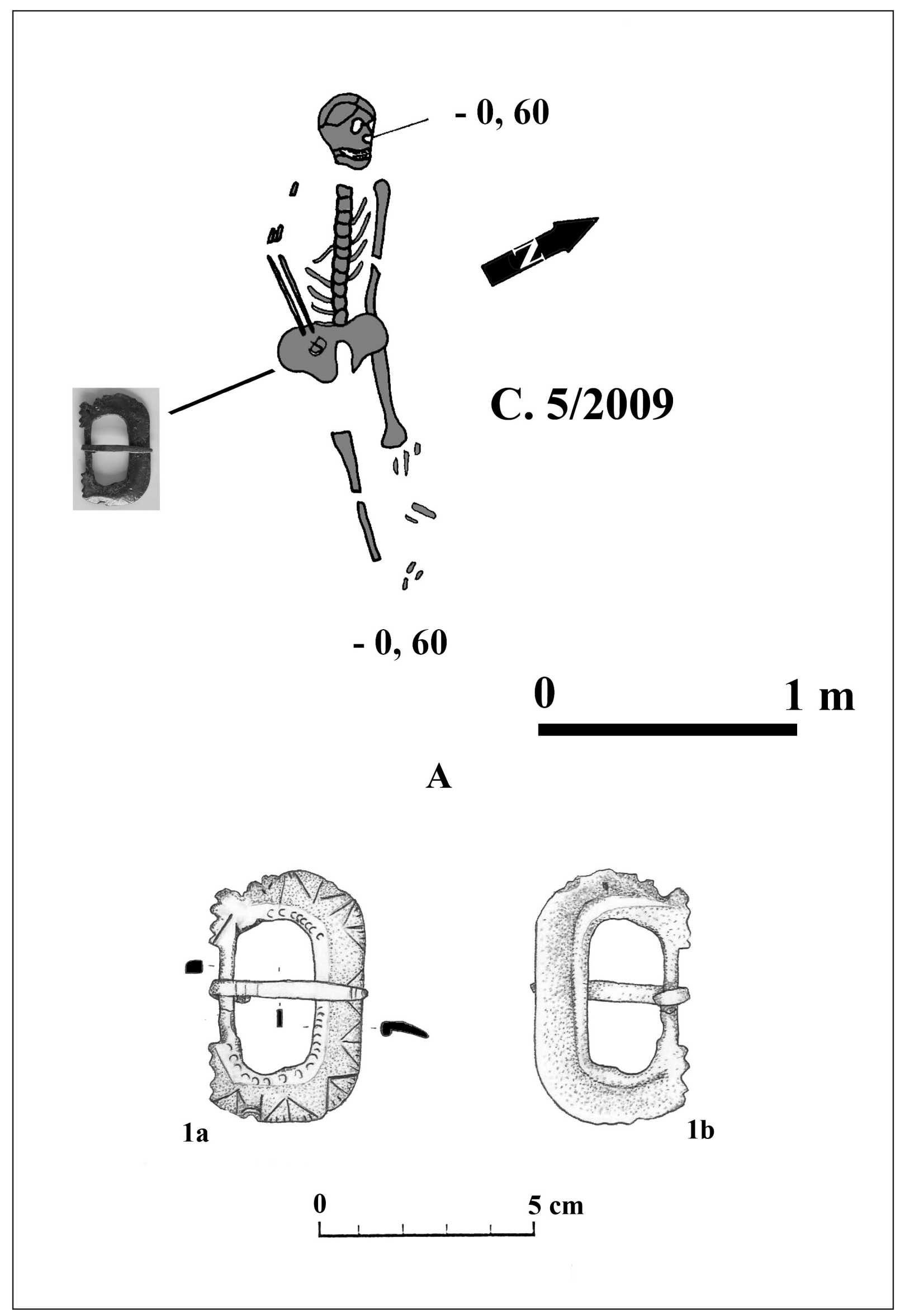

Pl. II. Ip - Dealul Bisericii. Complexul arheologic C. 5/2009 (A). Cataramă din bronz (1a-1b). 